\title{
EUV Resists based on Tin-Oxo Clusters
}

\author{
a College of Nanoscale Science and Engineering, Albany, NY 12033 \\ b State University of New York at New Paltz, New Paltz, NY 12561 \\ c Paul Scherrer Institut, Villigen, Switzerland \\ d Sematech, Albany NY 12033 \\ ¥Corresponding author: rbrainard@albany.edu, (518) 956-7320
}

Brian Cardineau, ${ }^{1}$ Ryan Del Re, ${ }^{1}$ Hashim Al-Mashat, ${ }^{2}$ Miles Marnell, ${ }^{2}$ Michaela Vockenhuber, ${ }^{3}$ Yasin Ekinci, ${ }^{3}$ Chandra Sarma, ${ }^{4}$ Mark Neisser, ${ }^{4}$ Daniel A. Freedman, ${ }^{2}$ and Robert L. Brainard ${ }^{1 ¥}$

\begin{abstract}
We have studied the photolysis of tin clusters of the type $\left[(\mathrm{RSn})_{12} \mathrm{O}_{14}(\mathrm{OH})_{6}\right] \mathrm{X}_{2}$ using extreme ultraviolet (EUV, $13.5 \mathrm{~nm})$ light, and developed these clusters into novel high-resolution photoresists. A thin film of $\left[(\mathrm{BuSn})_{12} \mathrm{O}_{14}(\mathrm{OH})_{6}\right][p \text {-toluenesulfonate }]_{2}(1)$ was prepared by spin coating a solution of $(\mathbf{I})$ in 2-butanone onto a silicon wafer. Exposure to EUV light caused the compound (1) to be converted into a substance that was markedly less soluble in aqueous isopropanol. To optimize the EUV lithographic performance of resists using tin-oxo clusters, and to gain insight into the mechanism of their photochemical reactions, we prepared several compounds based on $\left[(\mathrm{RSn})_{12} \mathrm{O}_{14}(\mathrm{OH})_{6}\right] \mathrm{X}_{2}$. The sensitivity of tin-oxide films to EUV light were studied as a function of variations in the structure of the counter-anions (X, primarily carboxylates) and organic ligands bound to tin $(\mathbf{R})$. Correlations were sought between the EUV sensitivity of these complexes vs. the strength of the carbon-carboxylate bonds in the counteranions and $v s$. the strength of the carbon-tin bonds. No correlation was observed between the strength of the carboncarboxylate bonds in the counter-anions (X) and the EUV photosensitivity. However, the EUV sensitivity of the tinoxide films appears to be well-correlated with the strength of the carbon-tin bonds. We hypothesize this correlation indicates a mechanism of carbon-tin bond homolysis during exposure. Using these tin clusters, 18-nm lines were printed showcasing the high resolution capabilities of these materials as photoresists for EUV lithography.
\end{abstract}

Keywords: Tin, Cluster, Photoresist, EUV, Photolysis, Organometallic.

\section{INTRODUCTION}

As the microelectronics industry continues to follow Moore's law, ${ }^{1}$ photoresist designers face ever-growing challenges associated with resolving increasingly smaller patterns. With 22-nm gate-lengths currently in production, many chip manufacturers are looking for ways to implement the 16 and 10-nm lithography nodes. Extreme ultraviolet (EUV, 13.5-nm wavelength) lithography is thought to be the next imaging technology for fabricating microelectronic devices, however, there are still many obstacles that must be overcome. The traditional, chemically-amplified photoresist systems which have been successful in lithography since the 1960s are finally encountering extremely challenging hurdles: (1) poor photon absorption in thin-films, (2) moderate etch selectivity, ${ }^{2,3}$ and (3) limited gains in resolution. ${ }^{4,5}$

Recently, two completely new resists have been developed based on hafnium-oxide nanoparticles. ${ }^{6-9}$ Researchers at Inpria, have developed one of the highest resolution EUV photoresists ever created. ${ }^{6}$ This resist has demonstrated resolution of 8-nm dense line and space patterns at $200 \mathrm{~mJ} / \mathrm{cm}^{2}{ }^{6}$ Christopher Ober's group at Cornell has also developed resists which utilize hafnium-oxide nanoparticles with equally remarkable performance. ${ }^{7-9}$ Although the Cornell resists (36-nm lines) do not have the high resolution capability of the Inpria resist, they are capable of excellent sensitivity $\left(12 \mathrm{~mJ} / \mathrm{cm}^{2}\right)$. The very notion of preparing photoresists using inorganic or organometallic compounds is still extremely new, but this pioneering work has demonstrated the great potential of inorganic systems as photoresists.

Advances in Patterning Materials and Processes XXXI, edited by Thomas I. Wallow, Christoph K. Hohle, Proc. of SPIE Vol. 9051, 90511B · (C) 2014 SPIE · CCC code: 0277-786X/14/\$18 · doi: 10.1117/12.2046536 
Here we describe the synthesis and lithographic evaluation of thin films of tin-oxo clusters $\left(\left[(\mathrm{RSn})_{12} \mathrm{O}_{14}(\mathrm{OH})_{6}\right] \mathrm{X}_{2}\right.$, Figure 1A) using extreme ultraviolet light (EUV, $13.5 \mathrm{~nm}$ ). These types of tin clusters have been known for over twenty years. ${ }^{10-46}$ They consist of spherical tin-oxo cages in which each of the twelve tin atoms is covalently bound to one organic $(\mathbf{R})$ group. The clusters have a +2 charge and are typically precipitated with pairs of anions $\left(\mathbf{X}^{-}\right)$. These materials have been investigated as self-assembled monolayer dopants, ${ }^{10}$ as esterification catalysts ${ }^{11}$ and as organometallic hybrid materials, ${ }^{12}$ but until now their photoreactivity has never been evaluated.

This investigation into the use of tin-oxide clusters as EUV photoresists has been motivated by three conclusions. (1) The work by Inpria and Cornell provided an excellent demonstration that metal-oxide nanoparticles/clusters could provide exceptional lithographic properties. (2) Both tin and oxygen readily absorb EUV photons with optical densities that are 10.5 and 1.7 times greater than carbon (Figure 2). ${ }^{47}$ We proposed that these higher optical densities should allow resists based on these tin-oxo clusters to better utilize the EUV photons that are used in EUV lithography to provide superior lithographic performance based on more efficient utilization of the EUV photons to give better sensitivity and lower shot noise. ${ }^{48}$ (3) The tin-oxo clusters are smaller and more uniformly sized than the $\mathrm{HfO}_{2}$ nanoparticles and should, therefore, be capable of excellent resolution and LER.

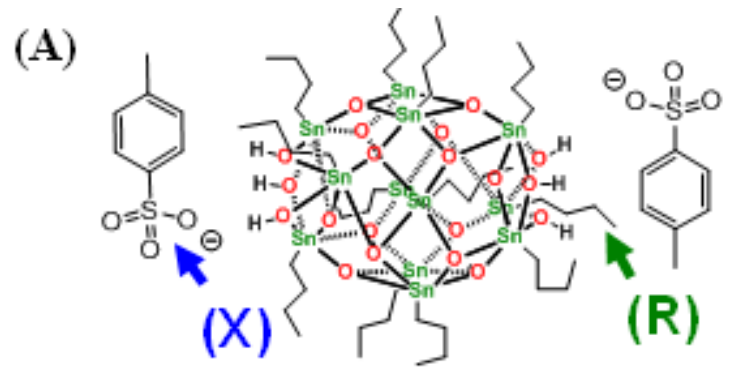

(B)

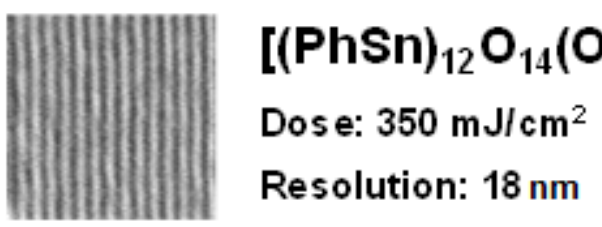

Figure 1. The mechanism of photolysis for Tin clusters of the type $\left[(\mathrm{RSn})_{12} \mathrm{O}_{14}(\mathrm{OH})_{6}\right] \mathrm{X}_{2}$ was explored through structural variation. (A) Clusters were made varying the bond energies of both the counter-ions (X) and the organic ligands (R) and tested for EUV lithographic performance. (B) Highest-resolution results for tin clusters. The best imaging was achieved by the clusters containing the phenyl organic ligands $(\mathbf{R})$, which was capable of $18-\mathrm{nm}$ resolutions. 

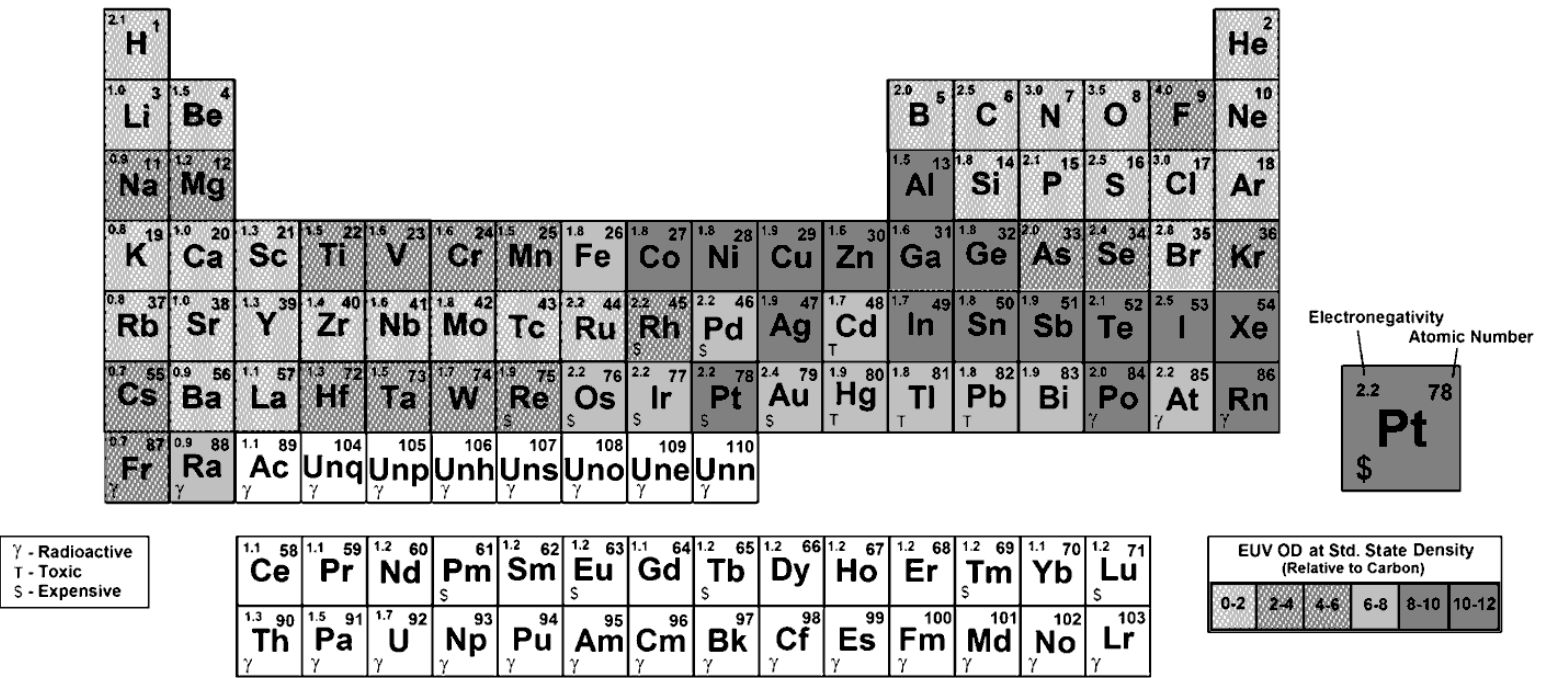

Figure 2. The periodic table with respect to EUV optical density.

In addition to preparing tin-oxo clusters that are known in the literature, we have made six new compounds. The lithographic performance of eight tin-oxo clusters were then evaluated lithographically using the EUV interference lithography tool at Paul Scherrer Institute (PSI) and the results were analysed.

\section{RESULTS AND DISCUSSION}

In an initial study, the tin-oxo cluster $\left[(\mathrm{n}-\mathrm{BuSn})_{12} \mathrm{O}_{14}(\mathrm{OH})_{6}\right]\left(\mathrm{p}^{-} \mathrm{CH}_{3} \mathrm{C}_{6} \mathrm{H}_{4} \mathrm{SO}_{3}\right)_{2}$ (1) was prepared as previously described in the literature. ${ }^{13}$ The tin cluster (1) was dissolved in 2-butanone and spin-coated into a thin film. The film was exposed to EUV light in an open field pattern using the Berkeley direct contrast tool (DCT) and developed in $66 \%$ aqueous isopropanol solvent for 30 seconds. ${ }^{49}$ Upon exposure to $20 \mathrm{~mJ} / \mathrm{cm}^{2}$ EUV light, the film became less soluble in developer - thereby exhibiting the properties of a negative-tone photoresist. In a related experiment, we were able to print 18-nm dense lines by exposing a film of $\left[(\mathrm{n}-\mathrm{BuSn})_{12} \mathrm{O}_{14}(\mathrm{OH})_{6}\right] \mathrm{Cl}_{2}$ using the interference lithographic tool at PSI. (Figure 1B).

Since these clusters exhibit photoreactivity and are capable of printing high resolution lines, we designed a set of experiments to explore their lithographic properties as a function of structure. Specifically, we prepared a series of compounds with variation in the carboxylate counter-anion and the alkyl group bound to tin with the hope of identifying which of these structural features participates in the exposure mechanism. Since the resolution capabilities of these clusters varies, yet all capable of printing 50-nm dense lines, we compared the amount of dose necessary to print 50-nm dense lines $\left(\mathrm{E}_{\text {size }}\right)$ as a function of variations in the structure of the carboxylate counter-anions $(\mathrm{X})$ and organic ligands bound to tin $(\mathrm{R})$.

\subsection{Counter-ion decomposition.}

There are several examples in the literature in which inorganic carboxylate complexes decompose via decarboxylation mechanisms. ${ }^{50-57}$ Following these literature examples, we reasoned that homolytic cleavage of the bond between carbon and carboxylate could produce $\mathrm{CO}_{2}$ and an alkyl radical (Figure 3). 


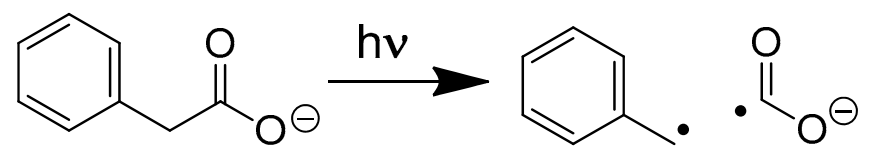

Figure 3. Photo-induced homolytic cleavage of phenylacetate. Phenylacetate is known to undergo a photochemical decarboxylation where generation of benzyl radical has been detected suggesting a homolytic cleavage mechanism. ${ }^{51,55-58}$

To determine the role that the anions have in the mechanism of photodecomposition, we prepared tin-oxo clusters with different carboxylate anions. Five carboxylic acids were selected for this study, with bond dissociation energies of the bond between carbon and carboxylate ranging from 67 to $103 \mathrm{kcal} / \mathrm{mol}$ (Table 1). ${ }^{59}$ In 1998, Eychenne-Baron et al. reported on the synthesis of compound 2 which has a hydroxide counter anion (Figure 4). ${ }^{13}$ Several literature examples demonstrate that the hydroxide can be replaced with various anions (X) upon reaction of 2 with one equivalent of acid $(\mathrm{HX})$ yielding $\left[(\mathrm{BuSn})_{12} \mathrm{O}_{14}(\mathrm{OH})_{6}\right] \mathrm{X}_{2} \cdot{ }^{12-15}$ Each acid was then combined with a stoichiometric amount of tin cluster (2) to produce the corresponding clusters (3) through (7).

\begin{tabular}{|c|c|c|}
\hline Acid (HX): & Structure: & $\begin{array}{l}\text { Bond Dissociation } \\
\text { Energy (kcal/mol): }\end{array}$ \\
\hline & (3) $\left[(\mathrm{BuSn})_{12} \mathrm{O}_{14}(\mathrm{OH})_{6}\right]\left[\mathrm{C}_{6} \mathrm{H}_{5} \mathrm{CH}_{2} \mathrm{COO}\right]_{2}$ & 67 \\
\hline & (4) $\left[(\mathrm{BuSn})_{12} \mathrm{O}_{14}(\mathrm{OH})_{6}\right][\mathrm{OCOCOO}]$ & 80 \\
\hline & (5) $\left[(\mathrm{BuSn})_{12} \mathrm{O}_{14}(\mathrm{OH})_{6}\right]\left[\mathrm{OCOCH} \mathrm{COO}_{2}\right.$ & $85^{*}$ \\
\hline & (6) $\left[(\mathrm{BuSn})_{12} \mathrm{O}_{14}(\mathrm{OH})_{6}\right][\mathrm{HCOO}]_{2}$ & 97 \\
\hline & (7) $\left[(\mathrm{BuSn})_{12} \mathrm{O}_{14}(\mathrm{OH})_{6}\right]\left[\mathrm{C}_{6} \mathrm{H}_{5} \mathrm{COO}\right]_{2}$ & 103 \\
\hline
\end{tabular}

Table 1. Five tin clusters were synthesized by combining the appropriate acid (HX) with the tin cluster hydroxide (2). The relative bond energy for each acid is also included and, if decomposition occurs, should correspond with the relative sensitivity. ${ }^{59}$ 


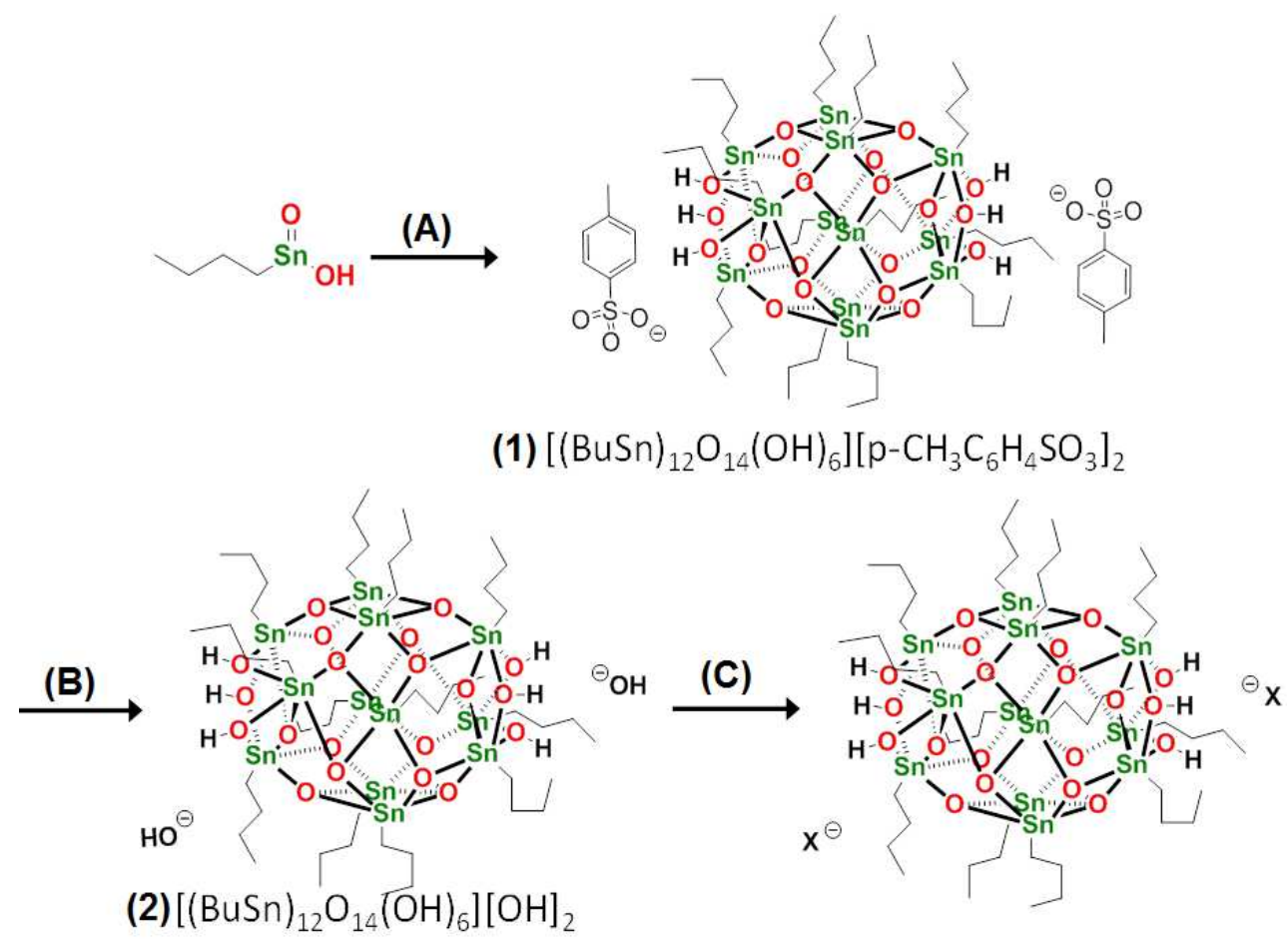

Figure 4. Synthetic pathway for tin clusters used in counter-ion decomposition study. (A) p-toluenesulfonic acid and toluene reflux, $48 \mathrm{hrs}(\mathrm{B})$ tetrabutylammonium hydroxide in isopropanol, crystallize at $-15{ }^{\circ} \mathrm{C}(\mathrm{C})$ Tetrahydrofuran and carboxylic acid, evaporate under reduced pressure. ${ }^{13,15}$

Clusters 3 through 7 were coated on wafers and exposed using the EUV interference lithographic tool at PSI, and developed. SEM images of the 50-nm dense patterns and the doses needed to reach equal lines and spaces $\left(\mathrm{E}_{\text {size }}\right)$ are shown (Figure 5A). We plotted the sensitivity of EUV imaging against the homolytic bond dissociation energies (Ccarboxylate bonds) to determine if the two values correlated (Figure 5B1). No correlation was observed. Instead, we found that resist sensitivity showed a functional dependence between the $\mathrm{E}_{\text {size }}$ and the counter-ion molecular weight (Figure 5B2). Our interpretation of this data is that the photoreaction occurs with the tin-oxide cation rather than the counter-ion, and the counter-ions only act as non-reactive spacers inhibiting the clusters from combining. 


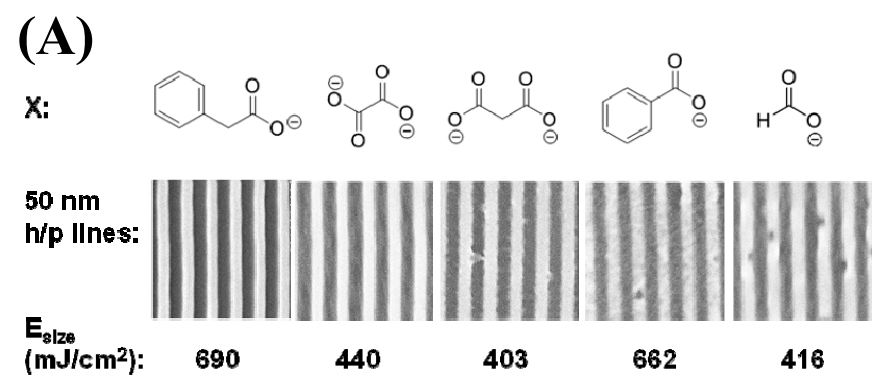

(B)

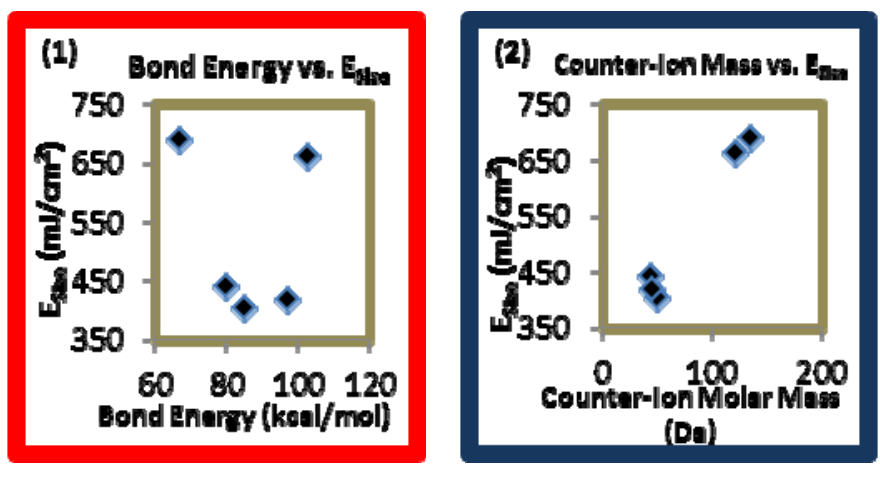

Figure 5. (A) Tin clusters of the type $\left[(\mathrm{BuSn})_{12} \mathrm{O}_{14}(\mathrm{OH})_{6}\right] \mathrm{X}_{2}$ were investigated lithographically and the relative sensitivity $\left(\mathrm{E}_{\mathrm{Size}}\right)$ was determined for each. (B1) Bond dissociation energy $v s$. $\mathrm{E}_{\text {size }}$ does not show any correlation. (B2) Ligand molecular weight $v s$. $\mathrm{E}_{\text {size }}$ suggests a functional dependence. These results suggest a mechanism involving the cluster core, not the counter-ion.

\subsection{Homolytic cleavage of the tin-carbon bond.}

A second possible reaction that could occur during exposure is homolytic cleavage of the tin-carbon bond. Tincarbon bonds are relatively weak $(\sim 50 \mathrm{kcal} / \mathrm{mol})$, and tin forms extremely stable radicals, therefore we reasoned that EUV exposure could cause homolysis of the Sn-C bond. ${ }^{60}$ If homolysis occurred, we predicted that stabilizing or destabilizing the organic radical should result in a change in the photosensitivity of the cluster. Figure 6A shows the C$\mathrm{H}$ bond dissociation energies of the three hydrocarbons. These $\mathrm{C}-\mathrm{H}$ bond energies predict the relative stabilization of their radical fragments. The goal of this study was to synthesize a series of tin clusters containing alkyl groups with different radical stabilities, and to then test these clusters for sensitivity and imaging. 
(A)

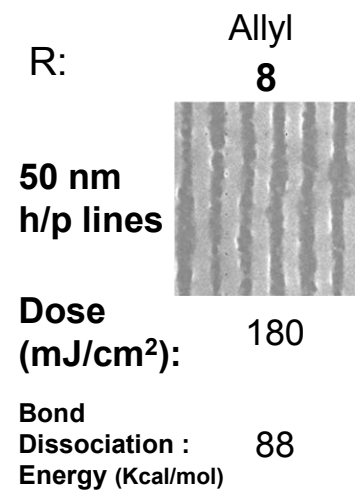

(B)

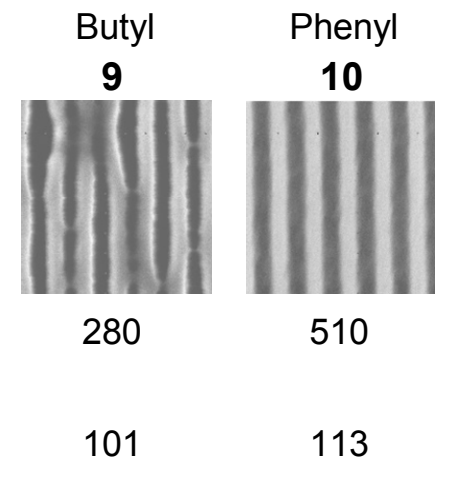

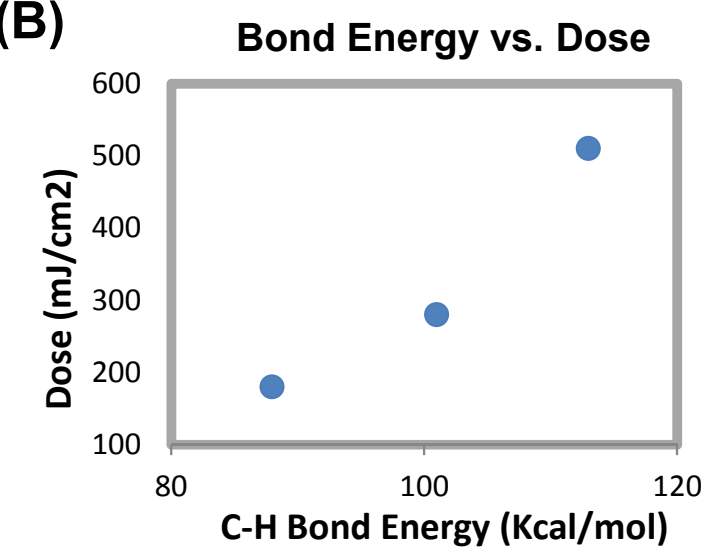

Figure 6. (A) The bond dissociation energies for three organic groups and lithographic results. By incorporating these groups into the tin clusters, a broad distribution of Sn-C bond energies should be achieved. ${ }^{59}$ (B) For the three clusters tested, there appears to be a direct correlation between the radical stability of the organic group and the sensitivity of the cluster which suggests that homolysis is occurring.

Few literature examples involved the synthesis of tin clusters with alkyl groups other than $n$-butyl and there were none with allyl or phenyl groups. This necessitated an exploration of the cluster synthesis. Tin clusters have been synthesized by either the dehydration of butylstannoic acid, ${ }^{13}$ or the controlled hydration of butyltin trichloride, ${ }^{12}$ butyltin trialkoxide ${ }^{16}$ or butyltin trialkyne. ${ }^{17}$ Since butylstannoic acid is generally made by rapid hydrolysis of butyltin trichloride, our starting material targets were alkyltin trichlorides. ${ }^{18}$ Allyltin trichloride was synthesized through a previously published route; phenyl and butyltin trichlorides were purchased. ${ }^{61}$ Our first attempts to synthesize the organostannoic acid, followed by dehydration to make the cluster (Figure 7A). Initial attempts with phenyltin trichloride, however, only yielded insoluble white solid (probably tin(IV) oxide due to hydrolysis of the phenyl-tin bond). Several hydrolysis methods were subsequently attempted, and hydrolysis of the organotin trichloride using ammonium hydroxide proved the most successful route (Figure 7B). The reaction product is a soluble polymeric material which has similar size to the tin cluster by gel permeation chromatography (GPC). Purification by successive precipitations in tetrahydrofuran and dichloromethane yielded a relatively monodisperse product by gel permeation chromatography. (GPC). ${ }^{1} \mathrm{H}$ NMR data confirmed the presence of the desired organic substituents. 


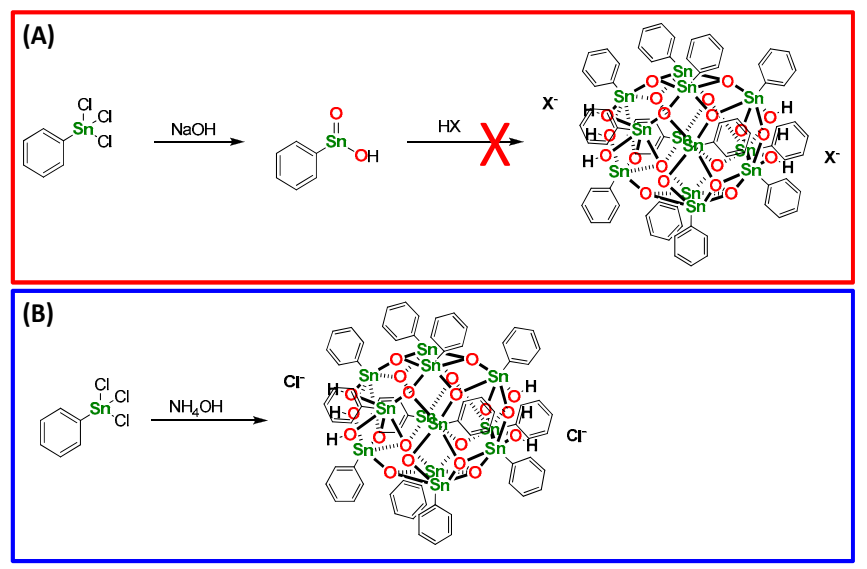

Figure 7. Synthesis of tin clusters from alkyltin trichlorides. (A) Initial attempts to synthesize the clusters by the conversion of phenyltin trichloride to phenylstannoic acid followed by dehydration failed. (B) Hydrolysis of phenyltin trichloride using ammonium hydroxide produces a soluble polymeric material which shows evidence that it is the tin cluster.

Clusters 8 through 10 were coated on wafers and tested lithographically (Figure 6A). Figure 6B shows the C-H bond energy $v s$. dose to $\mathrm{E}_{\text {size }}$ curve for the tin-oxo cluster. ${ }^{59}$ In general, the clusters with the weaker C-H bonds show the best sensitivity. This correlation supports a photolysis mechanism in which the homolysis of the tin-carbon bond is involved in the observed change in film dissolution rate.

\subsection{Interpretation of results.}

We have prepared a series of compounds to gain further insight into the mechanism of EUV imaging of tin-oxo clusters. In particular, the sensitivity of printing $50-\mathrm{nm}$ dense lines $\left(\mathrm{E}_{\text {size }}\right)$ was used as a measure of the photoreactivity arising from changes in the structures of the carboxylic counter-anions $(\mathbf{X})$ and the alkyl groups bonded to tin $(\mathbf{R})$. The sensitivity of the resists does not correlate with the strength of the carbon-carbonyl bonds, but shows a better correlation with the size (molecular weight) of the carboxylates. We therefore concluded that homolytic cleavage of the carboxylate was probably not important in the mechanism, but that the anions merely act as spacers between the cationic tin-oxo clusters. In contrast, however, the reactivity of the clusters are more correlated with the strength of the tin-carbon bonds, as the cluster with the weak tin-allyl bond gave the best sensitivity. Homolytic cleavage of the tin-carbon bond would produce tin-centered radicals which could initiate reactions with the adjacent cluster, creating cross-links, and ultimately agglomeration of the clusters. Large counter-ions would increase the space between clusters, interfering with this tin-tin bond formation and decreasing the resist sensitivity. 


\section{CONCLUSIONS}

The photochemistry of tin clusters has been investigated for EUV lithography. Here we have shown that tin clusters of the type $\left[(\mathrm{RSn})_{12} \mathrm{O}_{14}(\mathrm{OH})_{6}\right] \mathrm{X}_{2}$ can function as high-resolution photoresists for EUV lithography. To better understand this photochemistry, we investigated the effect of resist sensitivity of the structures of the carboxylic counter-anions $(\mathbf{X})$ and organic ligands $(\mathbf{R})$. The photosensitivity was not found to correlate with the counter-ion $(\mathbf{X})$ bond energy, but rather with molecular weight. Furthermore, the resist sensitivity was also found to correlate directly with the organic ligand $(\mathbf{R})$ bond energy. Both results support a mechanism of organic ligand (R) photolysis, activating the clusters for agglomeration and resulting in the observed the negative-tone imaging properties. Utilizing this photochemical change, we have resolved dense-line patterns as small as $18 \mathrm{~nm}$ (Figure 1B). Although the sensitivity of these tin clusters is poor, we hypothesize that by using higher-sensitivity ligands or alternate material sets, high-resolution resist materials can be made that can compete with photoresists based on conventional strategies using organic polymers.

\section{ACKNOWLEDGEMENTS}

We gratefully acknowledge Intel and Sematech for financial support of this work and the State University of New York at Albany for use of facilities. Part of this work was performed at Swiss Light Source (SLS), PSI, Switzerland.

\section{EXPERIMENTAL METHODS}

General. All reactions were carried out under a nitrogen atmosphere. The reagent butyltin hydroxide oxide was purchased from Alfa Aesar. Allyltin trichloride was synthesized through the previously published route. ${ }^{61}$ Phenyltin trichloride was purchased from Gelest and all other reagents were purchased from Sigma Aldrich. All reagents were used as received unless otherwise specified.

Instruments. Nuclear Magnetic Resonance (NMR) spectra were obtained using a Bruker 400 spectrometer. All chemical shifts are reported as parts per million ( $\mathrm{ppm}$ ) relative to residual proton peaks of the deuterated solvent. Gel Permeation Chromatography was performed using a Waters 1525 binary high pressure liquid chromatograph (HPLC) equipped with a Styrgel HR 4E THF gel permeation column and a Waters 2487 dual $\lambda$ Absorbance Detector set at 280 $\mathrm{nm}$. The column was calibrated using compounds 1 through 7.

General Resist Formulation and Imaging. Resist formulations were made by dissolving solids in 2-butanone and filtering through a $0.2 \mu \mathrm{m}$ PTFE filter. Formulations were then spincast onto 4-inch silicon wafers, precoated with an adhesion-promoting film (crosslinked hydroxyethyl methacrylate/methyl methacrylate copolymers). 40-nm thick resist films were made by adjusting spinspeed and formulation concentration. Resist films were then annealed with a $90{ }^{\circ} \mathrm{C}$ softbake, exposed with 13.5-nm radiation and developed with a isopropanol/water developing solution. Two exposure tools were used for this study: the Berkeley direct contrast tool (DCT) and the Paul-Scherrer Institut EUV interferometer. ${ }^{6}$ The Berkeley DCT has a beam diameter of $500 \mathrm{um}$ and a spectral bandwidth of about $\Delta \lambda / \lambda=1 / 300$.

General Synthetic Procedure for Compounds 3 through 7. Compound 2 ( $1.0 \mathrm{~g}, 0.41 \mathrm{mmol})$ was dissolved in tetrahydrofuran $(10 \mathrm{~mL})$ in a $50 \mathrm{~mL}$ round-bottom flask equipped with a stir-bar. Two molar equivalents $(0.82 \mathrm{mmol})$ of a $10 \%$ solution by weight of acid dissolved in tetrahydrofuran were added and the flask was stirred for ten minutes. The solvent was removed by vacuum and the compound was used as is. 
[(BuSn) $\left.)_{12} \mathbf{O}_{14}(\mathbf{O H})_{6}\right]\left[\mathbf{C}_{6} \mathbf{H}_{5} \mathbf{C H}_{2} \mathbf{C O O}\right]_{2}$ (3). Phenylacetic acid $(0.112 \mathrm{~g}, 0.82 \mathrm{mmol})$ was used as the acid. ${ }^{1} \mathrm{H}$ NMR (400 $\left.\mathrm{MHz} \mathrm{CDCl}_{3}\right) \delta 7.30(4 \mathrm{H}), 7.20(4 \mathrm{H}), 7.11(2 \mathrm{H}), 1.79(12 \mathrm{H}), 1.57(24 \mathrm{H}), 1.52(12 \mathrm{H}), 1.33(12 \mathrm{H}), 1.05(12 \mathrm{H}), 0.95$ $(18 \mathrm{H}), 0.88(18 \mathrm{H})$.

[(BuSn) $\left.{ }_{12} \mathbf{O}_{14}(\mathbf{O H})_{6}\right]\left[\mathbf{O C O C O O}\right.$ (4). Oxalic acid $(0.037 \mathrm{~g}, 0.41 \mathrm{mmol})$ was used as the acid. ${ }^{1} \mathrm{H}$ NMR $(400 \mathrm{MHz}$ $\left.\mathrm{CDCl}_{3}\right) \delta 1.76(12 \mathrm{H}), 1.61(12 \mathrm{H}), 1.54(12 \mathrm{H}), 1.48(12 \mathrm{H}), 1.32(12 \mathrm{H}), 1.06(12 \mathrm{H}), 0.94(18 \mathrm{H}), 0.87(18 \mathrm{H})$.

$\left[(\mathbf{B u S n})_{12} \mathbf{O}_{14}(\mathbf{O H})_{6}\right]\left[\mathbf{O C O C H} \mathbf{C O O}_{2} \mathbf{C O O}\right.$ (5). Malonic acid $(0.043 \mathrm{~g}, 0.41 \mathrm{mmol})$ was used as the acid. ${ }^{1} \mathrm{H}$ NMR (400 $\left.\mathrm{MHz} \mathrm{CDCl}_{3}\right) \delta 1.77(12 \mathrm{H}), 1.62(12 \mathrm{H}), 1.55(12 \mathrm{H}), 1.49(12 \mathrm{H}), 1.33(12 \mathrm{H}), 1.06(12 \mathrm{H}), 0.94(18 \mathrm{H}), 0.88(18 \mathrm{H})$.

$\left[(\mathbf{B u S n})_{12} \mathbf{O}_{14}(\mathbf{O H})_{6}\right]\left[\mathrm{HCOO}_{2} \mathbf{( 6 )}\right.$. Formic acid $(0.038 \mathrm{~g}, 0.82 \mathrm{mmol})$ was used as the acid. ${ }^{1} \mathrm{H}$ NMR $(400 \mathrm{MHz}$ $\left.\mathrm{CDCl}_{3}\right) \delta 8.40(2 \mathrm{H}), 1.82(12 \mathrm{H}), 1.66(24 \mathrm{H}), 1.54(12 \mathrm{H}), 1.34(12 \mathrm{H}), 1.13(12 \mathrm{H}), 0.97(18 \mathrm{H}), 0.89(18 \mathrm{H})$.

$\left[(\mathbf{B u S n})_{12} \mathbf{O}_{14}(\mathbf{O H})_{6}\right]\left[\mathbf{C}_{6} \mathbf{H}_{5} \mathbf{C O O}_{2} \mathbf{~ ( 7 )}\right.$. Benzoic acid $(0.100 \mathrm{~g}, 0.82 \mathrm{mmol})$ was used as the acid. ${ }^{1} \mathrm{H} \mathrm{NMR}(400 \mathrm{MHz}$ $\left.\mathrm{CDCl}_{3}\right) \delta 8.01(4 \mathrm{H}), 7.32(6 \mathrm{H}), 1.84(12 \mathrm{H}), 1.66(24 \mathrm{H}), 1.54(12 \mathrm{H}), 1.31(12 \mathrm{H}), 1.16(12 \mathrm{H}), 0.97(18 \mathrm{H}), 0.86(18$ $\mathrm{H})$.

General Synthetic Procedure for Compounds 8 through 10. Water $(20 \mathrm{~mL})$ was placed in a $50 \mathrm{~mL}$ round-bottom flask equipped with a stirbar and reflux condenser and nitrogen was bubbled through for ten minutes. The flask was placed under nitrogen, and ammonium hydroxide ( $25 \%$ solution, $6.309 \mathrm{~g}, 45 \mathrm{mmol}$ ) was added to the flask as the flask was cooled using an ice bath. Organotin trichloride was quickly added to the flask while stirring, and the solution was refluxed for 30 minutes. Upon completion, the flask was cooled to room temperature and filtered through celite. The celite was washed twice with tetrahydrofuran, and the combined organic and aqueous solutions were extracted three times with ethyl acetate. The organic phases were combined, dried over sodium sulfate and condensed under reduced pressure. The crude oil was then dissolved in diethyl ether and precipitated with hexane to yield a solid. The solid was then dried under vacuum.

$\left[\left(\mathbf{H}_{2} \mathbf{C}=\mathbf{C H C H}_{2} \mathbf{S n}\right)_{12} \mathbf{O}_{14}(\mathbf{O H})_{6}\right] \mathbf{C l}_{\mathbf{2}}(\mathbf{8})$. Allyltin trichloride $(3.992 \mathrm{~g}, 15 \mathrm{mmol})$ was used as the organotin trichloride. ${ }^{1} \mathrm{H}$ NMR $\left(400 \mathrm{MHz} \mathrm{CDCl}_{3}\right) \delta 6.13(1 \mathrm{H}), 5.34(1 \mathrm{H}), 5.30(1 \mathrm{H}), 2.50(2 \mathrm{H})$.

$\left[(\mathbf{B u S n})_{12} \mathbf{O}_{14}(\mathbf{O H})_{6}\right] \mathbf{C l}_{2}(9)$. Butyltin trichloride $(4.233,15 \mathrm{mmol})$ was used as the organotin trichloride. ${ }^{1} \mathrm{H}$ NMR $\left(400 \mathrm{MHz} \mathrm{CDCl}_{3}\right) \delta 1.84(2 \mathrm{H}), 1.79(2 \mathrm{H}), 1.72(2 \mathrm{H}), 1.63(2 \mathrm{H}), 1.52(2 \mathrm{H}), 1.81(2 \mathrm{H}), 0.97(3 \mathrm{H}), 0.88(3 \mathrm{H})$.

[(PhSn) $\left.)_{12} \mathbf{O}_{14}(\mathbf{O H})_{6}\right] \mathbf{C l}_{\mathbf{2}}$ (10). Phenyltin trichloride (4.533 g, $\left.15 \mathrm{mmol}\right)$ was used as the organotin trichloride. ${ }^{1} \mathrm{H}$ NMR $\left(400 \mathrm{MHz} \mathrm{CDCl}_{3}\right) \delta 7.10(5 \mathrm{H})$.

\section{REFERENCES}

[1] G. Moore, Electronics, 1965, 38.

[2] J. Paul, M. Rudolph, S. Riedel, S. Wege, C. Hohle and V. Beyer, The Electrochemical Society Abstract 2012.

[3] J. Paul, M. Rudolph, S. Riedel, X. Thrun, S. Wege and C. Hohle, Advanced Etch Technology for Nanopatterning II, Proceedings from SPIE 2013, 8685.

[4] S. Kang, W. L. Wu, K. W. Choi, A. DeSilva, C. K. Ober and V. M. Prabhu, Macromolecules, 2010, 43, 4275-4286.

[5] G. P. Patsis, V. Constantoudis and E. Gogolides, Microelectron. Eng., 2004, 75, 297-308.

[6] Y. Ekinci, M. Vockenhuber, M. Hojeij, L. Wang and N. Mojarad, Extreme Ultraviolet Lithography IV, Proceedings from SPIE, 2013, 8679, 867910 .

[7] M. Trikeriotis, M. Krysak, Y. Chung, C. Ouyang, B. Cardineau, R. L. Brainard, C. Ober, E. Giannelis and K. Cho, Proceedings from SPIE, 2012, 8322.

[8] M. Trikeriotis, W. Bae, E. Schwartz, M. Krysak, N.Lafferty, P. Xie, B. Smith, P. Zimmerman, C. Ober and E. Giannelis, Proceedings from SPIE, 2010, 7639, 76390E-76390E-76310. 
[9] W. Bae, M.Trikeriotis, J. Sha, E. Schwartz, R. Rodriguez, P. Zimmerman, E. Giannelis and C. Ober, Journal of Materials Chemistry, 2010, 20, 5186-5189.

[10] D. Constantin, B. Pansu, M. Imperor, P. Davidson and F. Ribot, Physical Review Letters, 2008, 101, 098101/098101098101/098104.

[11] T. Yano, N. Sakuta and J. Odera, Kobunshi Kako, 2001, 50, 225-229.

[12] W.-Q. Fan, J. Feng, S.-Y. Song, Y.-Q. Lei, G.-L. Zheng and H.-J. Zhang, Chemistry--A European Journal, 2010, 16, 1903-1910, S1903/1901-S1903/1903.

[13] C. Eychenne-Baron, F. Ribot and C. Sanchez, Journal of Organometallic Chemistry, 1998, 567, 137-142.

[14] F. Ribot, A. Lafuma, C. Eychenne-Baron and C. Sanchez, Advanced Materials (Weinheim, Germany), 2002, 14, $1496-1499$.

[15] L. Van Lokeren, R. Willem, D. van der Beek, P. Davidson, G. A. Morris and F. Ribot, Journal of Physical Chemistry C, 2010, 114, 16087-16091.

[16] F. Banse, F. Ribot, P. Toledano, J. Maquet and C. Sanchez, Inorganic Chemistry, 1995, 34, 6371-6379.

[17] P. Jaumier, B. Jousseaume, M. Lahcini, F. Ribot and C. Sanchez, Chemical Communications (Cambridge), 1998, $369-370$.

[18] D. Dakternieks, H. Zhu, E. R. T. Tiekink and R. Colton, Journal of Organometallic Chemistry, 1994, 476, 33-40.

[19] S. Durand, K. Sakamoto, T. Fukuyama, A. Orita, J. Otera, A. Duthie, D. Dakternieks, M. Schulte and K. Jurkschat, Organometallics, 2000, 19, 3220-3223.

[20] J. Beckmann, K. Jurkschat, U. Kaltenbrunner, S. Rabe, M. Schuermann, D. Dakternieks, A. Duthie and D. Mueller, Organometallics, 2000, 19, 4887-4898.

[21] R. Vivas-Reyes, F. De Proft, P. Geerlings, M. Biesemans, R. Willem, F. Ribot and C. Sanchez, New Journal of Chemistry, 2002, 26, 1108-1117.

[22] A. Orita, Y. Hamada, T. Nakano, S. Toyoshima and J. Otera, Chemistry--A European Journal, 2001, 7, $3321-3327$.

[23] F. Ribot, C. Eychenne-Baron and C. Sanchez, Materials Research Society Symposium Proceedings, 1998, 519, 29-40.

[24] F. Ribot, F. Banse, C. Sanchez, M. Lahcini and B. Jousseaume, Journal of Sol-Gel Science and Technology, 1997, 8, $529-533$.

[25] L. Angiolini, D. Caretti, R. De Vito, F. T. Niesel, E. Salatelli, C. Carlini, F. Ribot and C. Sanchez, Journal of Inorganic and Organometallic Polymers, 1997, 7, 151-162.

[26] F. Ribot, D. Veautier, S. Guillaudeu and T. Lalot, Journal of Sol-Gel Science and Technology, 2004, 32, 37-41.

[27] F. Ribot, F. Banse, F. Diter and C. Sanchez, New Journal of Chemistry, 1995, 19, 1145-1153.

[28] F. O. Ribot, C. Eychenne-Baron, F. Banse and C. Sanchez, Materials Research Society Symposium Proceedings, 1996, 435, 4354.

[29] J. Beckmann, D. Dakternieks, A. Duthie and E. R. T. Tiekink, Dalton Transactions, 2003, 755-759.

[30] H. Puff and H. Reuter, Journal of Organometallic Chemistry, 1989, 373, 173-184.

[31] D. Constantin, Journal of Chemical Physics, 2010, 133, 144901/144901-144901/144909.

[32] M. Izaaryene and H. Reuter, Phosphorus, Sulfur and Silicon and the Related Elements, 2011, 186, 1364-1366.

[33] W. Fan, J. Feng, S. Song, Y. Lei, L. Zhou, G. Zheng, S. Dang, S. Wang and H. Zhang, Nanoscale, 2010, 2, $2096-2103$.

[34] B. Zobel, J. Costin, B. R. Vincent, E. R. T. Tiekink and D. Dakternieks, Dalton, 2000, 4021-4022.

[35] H. Reuter and A. Sebald, Zeitschrift fuer Naturforschung, B: Chemical Sciences, 1993, 48, 195-198.

[36] G. Prabusankar, B. Jousseaume, T. Toupance and H. Allouchi, Angewandte Chemie, International Edition, 2006, 45, 1255-1258.

[37] L. Plasseraud, H. Cattey and P. Richard, Zeitschrift fuer Naturforschung, B: A Journal of Chemical Sciences, 2011 , 66, $262-268$.

[38] F. Ribot, D. Veautier, S. J. Guillaudeu and T. Lalot, J. Mater. Chem., 2005, 15, 3973-3978.

[39] A. Strachota, F. Ribot, L. Matejka, P. Whelan, L. Starovoytova, J. Plestil, M. Steinhart, M. Slouf, J. Hromadkova, J. Kovarova, M. Spirkova and B. Strachota, Macromolecules (Washington, DC, United States), 2012, 45, 221-237.

[40] F. Ribot, V. Escax, J. C. Martins, M. Biesemans, L. Ghys, I. Verbruggen and R. Willem, Chemistry--A European Journal, 2004, 10, 1747-1751.

[41] K. Ohkubo, S. C. Menon, A. Orita, J. Otera and S. Fukuzumi, Journal of Organic Chemistry, 2003, 68, $4720-4726$.

[42] C. Eychenne-Baron, F. Ribot, N. Steunou, C. Sanchez, F. Fayon, M. Biesemans, J. C. Martins and R. Willem, Organometallics, 2000, 19, 1940-1949.

[43] V. Chandrasekhar and R. Thirumoorthi, Organometallics, 2009, 28, 2096-2106.

[44] F. Ribot, E. Martinez-Ferrero, K. Boubekeur, P. M. S. Hendrickx, J. C. Martins, L. Van Lokeren, R. Willem and M. Biesemans, Inorganic Chemistry (Washington, DC, United States), 2008, 47, 5831-5840.

[45] F. Ribot, C. Sanchez, R. Willem, J. C. Martins and M. Biesemans, Inorganic Chemistry, 1998, 37, 911-917. 
[46] V. Chandrasekhar, R. Boomishankar, K. Gopal, P. Sasikumar, P. Singh, A. Steiner and S. Zacchini, European Journal of Inorganic Chemistry, 2006, 4129-4136.

[47] E. Gullikson, CXRO Filter Transmission. http://henke.lbl.gov/optical_constants/filter2.html, (1995-2010),

[48] R. L. Brainard, P. Trefonas, J. H. Lammers, et al., "Shot noise, LER, and quantum efficiency of EUV photoresists," Proc. SPIE 5374, 74-85 (2004).

[49] Dose Calibration Tool (DCT) - A tool designed and used at Lawrence Berkely National Laboratories used in the dose calibration of a resist. The resist-coated wafer is placed in the tool and exposed with 50 separate exposures; each exposure at a different dose. The wafer is then processed and the film thickness vs. dose curves is typically measured.,

[50] R. Okawara and M. Wade, Organotin Compounds, Dekker, New York, 1971.

[51] M. Lukeman, in CRC Handbook of Organic Photochemistry and Photobiology, CRC2012, ch. 29, pp. 715-726.

[52] E. Kupchik, Organotin Compounds, Dekker, New York, 1971.

[53] J. M. Hossenlopp, T. R. Viegut and J. A. Mueller, in Laser Chemistry of Organometallics: ACS Symposium Series, ed. J. Chaiken1993.

[54] W. M. Horspool, in Photochemistry, RSC1994, vol. 25, pp. 1-16.

[55] A. G. Griesbeck, W. Kramer and M. Oelgemoller, Synlett, 1999, 7, 1169-1178.

[56] S. Farhadi, P. Zaringhadam and R. Z. Sahamieh, Tetrahedron Letters, 2006, 47, 1965-1968.

[57] D. Budac and P. Wan, Journal of Photochemistry and Photobiology A: Chemistry, 1992, 67, 135-166.

[58] A. Poznyak and V. Pavlovski, Angewandte Chemie, 1988, 27, 789-796.

[59] Y.-R. Luo, Handbook of Bond Dissociation Energies in Organic Compounds, CRC Press LLC, New York, 2003.

[60] E. W. Abel, G. A. Stone and G. Wilkinson, Comprehensive Organometallic Chemistry II, Pergamon.

[61] T. Strenalyuk, S. Samdal, H. Møllendal and J.-C. Guillemin, Organometallics, 2006, 25, 2626-2633. 